\title{
Conhecimento pedagógico do conteúdo: cenário das pesquisas brasileiras nos contextos da licenciatura e da docência em matemática (2001-2018)
}

\section{RESUMO}

Odiméia Teixeira odimeiat@yahoo.com.br Prcid.org/0000-0001-5862-595X de Ciências e Educação Matemática de Ciências e Educação Matemática Ponta Grossa (UEPG), Ponta Grossa, Paraná, Brasil

Mary Ângela Teixeira Brandalise marybrandalise@uol.com.br orcid.org/0000-0003-3674-5314 Universidade Estadual de Ponta Grossa (UEPG), Ponta Grossa, Paraná, Brasil

\begin{abstract}
Este artigo apresenta uma revisão sistemática da literatura referente ao Conhecimento Pedagógico do Conteúdo dos professores no contexto da Licenciatura e da docência em Matemática. A pesquisa foi realizada no primeiro semestre de 2018 com o objetivo de identificar na produção acadêmica brasileira, teses e dissertações, fundamentadas no referencial teórico da Base de Conhecimentos para a Docência, de Lee Shulman, desenvolvidas no período de 2001 a 2018. A base de dados utilizada para o levantamento foi o Catálogo de Teses e Dissertações do Portal da CAPES e os sites de bibliotecas de instituições de origem das pesquisas. Das produções localizadas, 21 foram selecionadas e seus resumos analisados quanto ao objeto de investigação. Assim, elas foram agrupadas conforme a similaridade das suas temáticas. Os resumos das produções acadêmicas foram reunidos e formaram um corpus textual que foi analisado com apoio do software Iramuteq. Os relatórios de análise lexicográfica, análise de similitude, classificação hierárquica descendente e análise fatorial gerados no software demonstraram que, nas pesquisas mapeadas, o Conhecimento Pedagógico do Conteúdo esteve relacionado a estudos referentes à análise do currículo dos cursos de Licenciatura, à formação inicial e continuada de professores, à Licenciatura em Matemática e às questões de ensino e de aprendizagem da Matemática, predominantemente na perspectiva de professores da Educação Básica. Enfim, a revisão sistemática possibilitou identificar em quais contextos, da Licenciatura e da docência em Matemática, o Conhecimento Pedagógico do Conteúdo vem sendo abordado como referencial teórico nas pesquisas, revelando a lacuna de investigações com foco no professor formador da Licenciatura em Matemática.
\end{abstract}

PALAVRAS-CHAVE: Conhecimento Pedagógico do Conteúdo. Licenciatura e Docência em Matemática. Professor Formador. Revisão Sistemática. Software Iramuteq. 


\section{INTRODUÇÃO}

Esta pesquisa, caracterizada como uma revisão sistemática de literatura foi realizada com o objetivo de conhecer a produção acadêmico-científica desenvolvida no período de 2001 a 2018 no Brasil. Está fundamentada no referencial teórico da Base de Conhecimentos para a Docência, especificamente em relação ao Conhecimento Pedagógico do Conteúdo do professor, no contexto da Licenciatura e da docência em Matemática.

Corresponde a uma etapa preliminar da pesquisa de Mestrado da primeira autora, trabalho que tem como objeto de estudo a Base de Conhecimentos para a Docência e o Conhecimento Pedagógico do Conteúdo (Pedagogical Content Knowledge - PCK) ${ }^{1}$ dos professores formadores de cursos de Licenciatura em Matemática do Estado do Paraná, atuantes nos componentes curriculares que abordam a Metodologia da Resolução de Problemas como um conteúdo específico. Os conceitos de Base de Conhecimentos para a Docência e de PCK adotados na pesquisa aportam-se nos pressupostos de Lee Shulman (1986, 1987), os quais foram propostos com o objetivo de colaborar para o desenvolvimento profissional dos professores e de contribuir para a melhoria dos processos de ensino e de aprendizagem.

Os estudos de Shulman (1987) propõem uma Base de Conhecimentos para a Docência, denominada originalmente de Knowledge base for teaching, a qual é composta por: conhecimento do conteúdo específico, conhecimento pedagógico geral, conhecimento curricular, conhecimento pedagógico do conteúdo, conhecimento dos alunos e suas características, conhecimento dos contextos educativos e conhecimento dos fins, dos propósitos e dos valores educacionais, e seus fundamentos filosóficos e históricos.

Todavia, o foco principal da Base de Conhecimentos para a Docência, segundo Shulman (1987), centra-se no desenvolvimento do PCK, o qual, na concepção do autor, é o que distingue um professor de um especialista bacharel na matéria. Esse conhecimento constitui-se a partir de um processo dinâmico e cíclico de reflexão e de ação e se concretiza quando o professor, com o objetivo de transformar seu conhecimento específico sobre determinado conteúdo, em um conhecimento que seja compreensível pelos alunos, faz uso de estratégias diversificadas, como explanações, ilustrações, metáforas, representações ou situações-problema. Sobre a base de conhecimentos necessária à atuação docente, Santos e Freire (2017) afirmam:

A literatura internacional, em especial da área de ensino de ciências, tem apontado uma base de conhecimentos para professores que delimita e caracteriza essa profissão (FERNANDEZ, 2015). Dentre estes, recebe destaque o conceito de Conhecimento Pedagógico do Conteúdo, PCK, do inglês Pedagogical Content Knowledge, e que representa o conhecimento próprio do professor utilizado no processo de ensino, que se constitui a partir da integração do conteúdo específico de uma disciplina com pressupostos da pedagogia. (SANTOS; FREIRE, 2017, p. 4).

Cabe salientar também que, em países como os Estados Unidos, a Austrália, a Inglaterra e o Canadá, os estudos de Shulman $(1986,1987)$ e seus colaboradores constituem-se como importante referencial para muitas pesquisas em educação e ensino, nas mais diversas áreas de conhecimentos, por isso o 
interesse em conhecer em que aspectos esse referencial vem sendo adotado no Brasil, como fundamentação teórica nas pesquisas voltadas ao Conhecimento Pedagógico do Conteúdo do professor de Matemática.

Para atender aos objetivos da pesquisa, foi realizada, no primeiro semestre de 2018, a consulta no Catálogo de Teses e Dissertações do Portal da Coordenação de Aperfeiçoamento de Pessoal de Nível Superior (CAPES) e nos sites de bibliotecas das instituições de origem das pesquisas, a fim de identificar as produções acadêmicas na área de interesse e de constituir o corpus textual da revisão sistemática. Após o refinamento dos 107 trabalhos listados na consulta inicial, foram selecionados 21 publicados entre os anos de 2001 e 2018 (1을 semestre), desenvolvidos no contexto da Licenciatura e da docência em Matemática.

Na sequência, são apresentados os procedimentos escolhidos para condução da revisão de literatura, a descrição do software Iramuteq adotado como recurso metodológico para a análise das produções acadêmicas; a sistematização e a discussão das análises realizadas a partir do referido software; e a apresentação das considerações finais referentes aos resultados discutidos neste artigo.

\section{O DESENVOLVIMENTO DA PESQUISA}

Em termos metodológicos, este artigo apresenta procedimentos mistos, em uma perspectiva quali-quantitativa, caracterizada como uma revisão sistemática de literatura. Pesquisas desse gênero são, de acordo com Davies (2007),

[...] uma forma de síntese de pesquisa que contribui para as políticas e práticas baseadas em evidências ao identificar as evidências de pesquisa acumulada sobre um tópico ou uma questão, avaliando-as criticamente em relação a sua metodologia e suas conclusões e determinando as mensagens coerentes e variáveis que são geradas por esse corpus de trabalho. As revisões sistemáticas das evidências de pesquisa existentes também ajudam a identificar o que se conhece sobre um tópico ou questão e, assim, direcionar novas pesquisas primárias nas áreas em que haja uma lacuna na base de evidências. (DAVIES, 2007, p. 32).

As pesquisas que se caracterizam como revisão sistemática de literatura são aquelas que objetivam "[...] sintetizar as temáticas abordadas, as abordagens teórico-metodológicas empregadas, tendências gerais de investigação, contribuições dos estudos, lacunas e sínteses das conclusões" (MAINARDES, 2009, p. 8). Assim sendo, para o seu desenvolvimento, foram consideradas as teses e as dissertações produzidas no Brasil em programas de pós-graduação stricto sensu, no período compreendido entre os anos de 2001 a 2018 (10 semestre), as quais se encontravam disponibilizadas no Catálogo de Teses e Dissertações do Portal da CAPES. Tendo em vista que, nesse portal, não estavam disponibilizados os links de acesso às publicações do período anterior ao ano de 2013, foi necessário o acesso ao site das bibliotecas depositárias de cada uma das produções acadêmicas anteriores a esse período, com a finalidade de obtê-las na íntegra para compor a revisão de literatura.

Como descritor, foi utilizado o termo "Conhecimento Pedagógico do Conteúdo", resultando, inicialmente, em uma relação de 107 trabalhos, entre dissertações e teses nas mais diversas áreas de conhecimentos, as quais são 
apresentadas no Quadro 1, nos respectivos anos de publicação. Nele, é possível perceber o gradativo e significante aumento das pesquisas desenvolvidas segundo o PCK, de 2001 até 2018. Utilizou-se no quadro seguinte, QT representando quantidade das pesquisas produzidas em cada ano.

Quadro 1 - Relação das áreas de conhecimentos e número de publicações referentes ao PCK, no Brasil, no período de 2001 a 2018

\begin{tabular}{|c|c|c|c|c|}
\hline Tipo/QT & $\begin{array}{l}\text { Grande área de } \\
\text { conhecimento }\end{array}$ & Área de conhecimento & Ano & QT \\
\hline \multirow{16}{*}{ 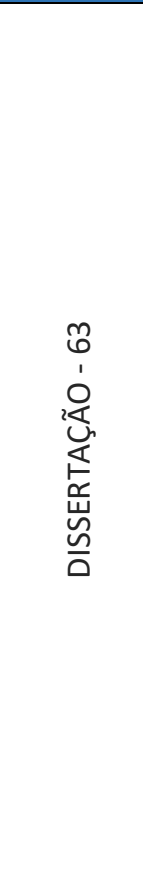 } & \multirow{16}{*}{$\begin{array}{l}\text { Ciências Biológicas (2) } \\
\text { Ciências da Saúde (2) } \\
\text { Ciências Humanas (18) } \\
\text { Linguística, Letras } \\
\text { e Artes (2) } \\
\text { Multidisciplinar (39) }\end{array}$} & \multirow{16}{*}{$\begin{array}{c}\text { Botânica (2) } \\
\text { Educação (15) } \\
\text { Educação Física (1) } \\
\text { Enfermagem (1) } \\
\text { Ensino (15) } \\
\text { Ensino de Ciências } \\
\text { e Matemática (23) } \\
\text { Geografia (3) } \\
\text { Música (2) } \\
\text { Ciências Sociais e } \\
\text { Humanas (1) }\end{array}$} & 2001 & 1 \\
\hline & & & 2002 & 3 \\
\hline & & & 2003 & 1 \\
\hline & & & 2005 & 2 \\
\hline & & & 2007 & 2 \\
\hline & & & 2008 & 1 \\
\hline & & & 2009 & 1 \\
\hline & & & 2010 & 3 \\
\hline & & & 2011 & 5 \\
\hline & & & 2012 & 7 \\
\hline & & & 2013 & 6 \\
\hline & & & 2014 & 6 \\
\hline & & & 2015 & 6 \\
\hline & & & 2016 & 8 \\
\hline & & & 2017 & 9 \\
\hline & & & 2018 & 2 \\
\hline \multirow{12}{*}{$\begin{array}{l}\text { 寸 } \\
\text { 岃 } \\
\text { 山ै }\end{array}$} & \multirow{12}{*}{$\begin{array}{c}\text { Ciências da Saúde (5) } \\
\text { Ciências Exatas e da } \\
\text { Terra (1) } \\
\text { Ciências Humanas (19) } \\
\text { Linguística, Letras } \\
\text { e Artes (1) } \\
\text { Multidisciplinar (18) }\end{array}$} & \multirow{12}{*}{$\begin{array}{c}\text { Educação (18) } \\
\text { Enfermagem (4) } \\
\text { Ensino (3) } \\
\text { Ensino de Ciências } \\
\text { e Matemática (13) } \\
\text { Geografia (1) } \\
\text { Música (1) } \\
\text { Odontopediatria (1) } \\
\text { Química (1) } \\
\text { Sociais e Humanidades (2) }\end{array}$} & 2002 & 1 \\
\hline & & & 2003 & 1 \\
\hline & & & 2006 & 1 \\
\hline & & & 2007 & 4 \\
\hline & & & 2010 & 2 \\
\hline & & & 2012 & 3 \\
\hline & & & 2013 & 4 \\
\hline & & & 2014 & 6 \\
\hline & & & 2015 & 10 \\
\hline & & & 2016 & 2 \\
\hline & & & 2017 & 9 \\
\hline & & & 2018 & 1 \\
\hline
\end{tabular}

Fonte: Autoria própria (2018).

Diante do número de trabalhos e da diversidade das áreas identificadas, foram necessárias a leitura e a análise dos títulos e dos resumos das produções a fim de realizar o refinamento da busca, de modo a considerar somente as pesquisas voltadas à Licenciatura e à docência em Matemática. O processo de análise e de refinamento resultou em um total de 21 trabalhos, distribuídos entre 
13 dissertações e 8 teses, sendo as primeiras desenvolvidas somente no ano de 2007, conforme apresentado na Tabela 1:

Tabela 1 - Quantitativo de produções acadêmicas no contexto da Licenciatura e da docência em Matemática fundamentadas teoricamente no PCK - 2007 a 2018

\begin{tabular}{|c|c|c|c|c|}
\hline \multirow{2}{*}{ Ano } & \multicolumn{5}{|c|}{ Produção } \\
\cline { 2 - 5 } & Dissertação & Tese & Total & $(\mathbf{\%})$ \\
\hline 2007 & 1 & 2 & 3 & 14,3 \\
\hline 2008 & 0 & 0 & 0 & 0 \\
\hline 2009 & 0 & 0 & 0 & 0 \\
\hline 2010 & 1 & 0 & 1 & 4,8 \\
\hline 2011 & 0 & 0 & 0 & 0 \\
\hline 2012 & 2 & 0 & 2 & 9,5 \\
\hline 2013 & 1 & 1 & 2 & 9,5 \\
\hline 2014 & 4 & 1 & 5 & 23,8 \\
\hline 2015 & 2 & 2 & 4 & 19,1 \\
\hline 2016 & 1 & 1 & 2 & 9,5 \\
\hline 2017 & 1 & 1 & 2 & 9,5 \\
\hline 2018 & 0 & 0 & 0 & 0 \\
\hline Total & 13 & 8 & 21 & 100 \\
\hline
\end{tabular}

Fonte: Autoria própria (2018).

Dos dados registrados na Tabela 1 , constata-se maior incidência de dissertações - 13 (61,9\%) - em comparação ao número de teses - 8 (38,1\%). A maior concentração das pesquisas aconteceu nos anos de 2014 e 2015, com $(23,8 \%)$ e $(19,1 \%)$, respectivamente. Além disso, observa-se a ausência de pesquisas brasileiras a respeito do Conhecimento Pedagógico do Conteúdo, nos anos de 2008, 2009, 2011 e 2018, no contexto em questão.

A leitura e a análise dos resumos das produções acadêmicas permitiram identificar as similaridades das pesquisas em relação ao foco de investigação e organizá-las em quatro grupos, conforme apresentado na Tabela 2, onde utilizouse ID no que concerne a identificação das pesquisas e QT representando a quantidade de trabalhos encontrados.

Tabela 2 - Agrupamento das produções acadêmicas - 2007 - 2018

\begin{tabular}{|c|c|c|c|c|}
\hline ID & Grupos & Autores/Ano & (QT) & Total \\
\hline 1 & $\begin{array}{l}\text { PCK na perspectiva de } \\
\text { análise do Currículo e dos } \\
\text { Projetos Pedagógicos de } \\
\text { Cursos (PPCs) de } \\
\text { Licenciatura em Matemática }\end{array}$ & $\begin{array}{c}\text { Wolski (2007); Silva, L. D. } \\
\text { (2015); Resende (2007); Guerra } \\
\text { (2013); Lima (2014). }\end{array}$ & 5 & $23,8 \%$ \\
\hline II & $\begin{array}{c}\text { PCK na perspectiva da } \\
\text { formação continuada de } \\
\text { professores de Matemática }\end{array}$ & $\begin{array}{c}\text { Costa (2013); Maroquio (2014); } \\
\text { Garnier (2015). }\end{array}$ & 3 & $14,3 \%$ \\
\hline III & $\begin{array}{l}\text { PCK na perspectiva de } \\
\text { professores atuantes na } \\
\text { Educação Básica }\end{array}$ & $\begin{array}{c}\text { Ferreira (2014); Souza (2015); } \\
\text { Leite (2016); Oliveira (2016); } \\
\text { Batista (2012); Furoni (2014); } \\
\text { Matos (2017); Machado (2017). }\end{array}$ & 8 & $38,1 \%$ \\
\hline IV & $\begin{array}{c}\text { PCK na formação Inicial de } \\
\text { professores de Matemática } \\
\text { - perspectiva dos } \\
\text { licenciandos }\end{array}$ & $\begin{array}{c}\text { Damico (2007); Silva, J. F. } \\
\text { (2017); Silva, R. G. (2010); } \\
\text { Correia (2012); Fantinel (2015). }\end{array}$ & 5 & $23,8 \%$ \\
\hline \multicolumn{3}{|c|}{ Total } & 21 & $100 \%$ \\
\hline
\end{tabular}

Fonte: Autoria própria (2018). 
Os Grupos I e IV, ambos compostos por 23,8\% das pesquisas, concentraram trabalhos voltados aos cursos de Licenciatura em Matemática, de forma que as pesquisas do primeiro agrupamento (I) tiveram o foco no Currículo e nos Projetos Pedagógicos de Cursos de Licenciatura em Matemática em relação ao PCK. No quarto agrupamento (IV), concentraram-se as pesquisas que abordaram o PCK na formação inicial de professores de Matemática, considerando, todavia, a perspectiva dos licenciandos dessa área.

O grupo II (14,3\%) concentrou as pesquisas que investigaram o PCK na formação continuada de professores de Matemática; e o grupo III (38,1\%) foi o grupo com número mais expressivo de pesquisas, no qual foram reunidas as investigações com foco na análise do PCK de professores atuantes na Educação Básica.

Em termos de distribuição geográfica, no gráfico contido na Figura 1, é possível observar a produção acadêmica conforme a região de origem.

Figura 1 - Distribuição geográfica das teses e das dissertações de acordo com o agrupamento por similaridade

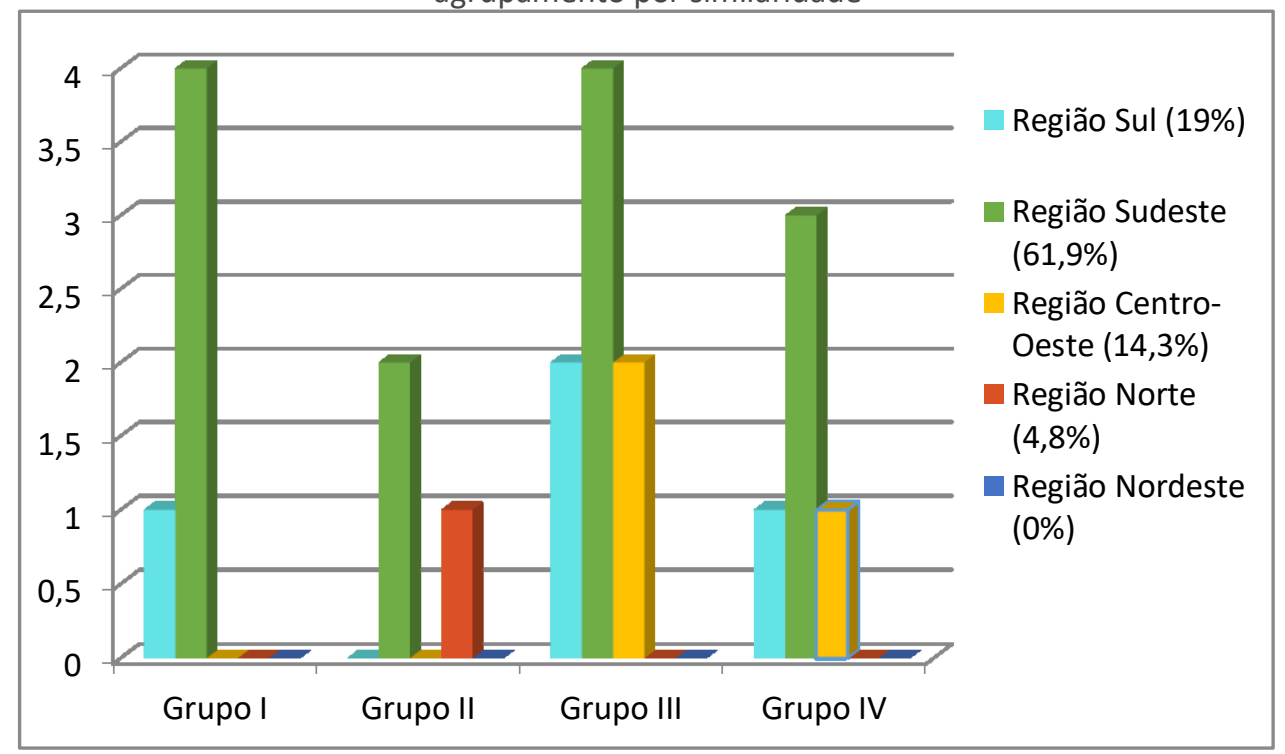

Fonte: Autoria própria (2018).

A maior concentração de trabalhos foi na região Sudeste $(61,9 \%)$, seguida da região Sul $(19,0 \%)$ e Centro-Oeste (14,3\%). As regiões Norte e Nordeste $(4,8 \%$ e $0 \%$, respectivamente) foram as regiões com menor índice de publicações a respeito do tema desta revisão sistemática.

Além da análise empírica dos resumos selecionados, a qual permitiu a organização das pesquisas em quatro grupos distintos de acordo com o foco de investigação, foi utilizado o software Iramuteq, com a finalidade de aprofundar a análise textual dos resumos selecionados em uma perspectiva quali-quantitativa.

$\mathrm{Na}$ próxima seção, são apresentadas algumas das características e especificidades do software Iramuteq, bem como o detalhamento da preparação do corpus textual para torná-lo compatível ao funcionamento do programa. 


\section{O SOFTWARE IRAMUTEQ COMO RECURSO METODOLÓGICO PARA ANÁLISE DAS PRODUÇÕES ACADÊMICAS}

O Iramuteq é um software livre, desenvolvido no ano de 2009 por Pierre Ratinaud (CAMARGO; JUSTUS, 2013), na linguagem Python, ancorado em funcionalidades providas pelo software $R$ e licenciado por GNU GPL (v2). De acordo com Camargo e Justo (2013), é um programa informático que possibilita diferentes tipos de análise de corpus textual, dentre elas: a) análise lexicográfica, a qual indica a frequência de palavras; b) identificação e busca de palavras de acordo com as classes gramaticais e busca de palavras com base na raiz (lematização); c) pesquisa de especificidade de grupos; d) classificação hierárquica descendente - CHD (por consequência análise fatorial de correspondência- AFC); d) análise de similitude, entre outros.

Nas análises de dados textuais simples, é possível realizar cálculos de frequência de palavras, que podem ser representadas graficamente em uma figura denominada nuvem de palavras. Nas análises multivariadas, de caráter mais sofisticado, são possíveis as análises de CHD, de AFC e de similitude (CAMARGO; JUSTUS, 2013), representadas por gráficos denominados dendograma, plano fatorial e árvore de similitude, respectivamente.

A utilização do software Iramuteq em pesquisas qualitativas teve início a partir do ano de 2013, principalmente nas pesquisas voltadas à Representação Social, e foi gradativamente se expandindo para outras áreas. Dentre as vantagens da sua utilização na análise textual, salienta-se o aumento na eficiência dos procedimentos e a facilidade na localização de fragmentos textuais, além da agilidade no processo de codificação e de categorização de corpus textuais.

Para que fosse utilizado o software Iramuteq, foi realizada, inicialmente, a preparação do corpus textual e a organização do conjunto de textos a serem analisados, constituído pelo conjunto de resumos das dissertações e das teses mapeadas. O preparo seguiu as orientações do tutorial do programa Iramuteq ${ }^{2}$, e assim, consistiu o trabalho de configuração dos resumos para rodar no programa, com procedimentos de junção de palavras e eliminação de acentuação e símbolos ${ }^{3}$.

Além disso, os resumos das produções acadêmicas selecionadas foram codificados e separados por linhas de comandos denominadas linhas com asteriscos, conforme originários de dissertação ou de tese, seguindo a numeração até que todos os resumos das pesquisas fossem nomeados, conforme os exemplos a seguir: estudo sobre o conhecimento_pedagogico dos numeros_racionais investigou como se apresenta o conhecimento_pedagogico dos numeros_racionais com professores_de_matematica durante a sua pratica em parceria com o projeto do Observatorio da Educacao da UFABC, e esta baseada na pratica construida a partir da nocao de conhecimento_pedagogico_do_conteudo (PCK) de Shulman (1987) ampliada por Ball, Thames e Phelps (2008) no que chamam de MKT. $[\ldots]$ 
$* * * * *$ tese_3

Nesta pesquisa objetivamos compreender os tipos de conhecimentos presentes nos PPCs e Planos de Ensino da Disciplina de Analise nos cursos de Licenciatura_em_Matematica no Brasil. Na busca de contemplarmos este objetivo, definimos a seguinte questao norteadora: Quais sao os tipos de conhecimentos presentes nos PPCs e Planos de Ensino da Disciplina de Analise dos cursos de Licenciatura_em_Matematica no Brasil? [...]

O corpus textual construído foi revisado, salvo no formato txt e inserido no Iramuteq para o processamento dos dados, gerando relatórios e gráficos, que possibilitaram a realização de uma análise quali-quantitativa. No processamento das informações contidas no corpus textual, o programa reconheceu 21 textos que correspondiam aos resumos das teses e das dissertações; gerou 195 segmentos de textos, dos quais $70 \%$ foram classificados (130); e definiu 1.248 formas ativas, que são palavras com frequência igual ou superior a 3 .

Para compor a revisão de literatura, foram considerados quatro tipos de análises originárias dos relatórios do Iramuteq sobre as produções acadêmicas mapeadas, a saber: análise lexicográfica, análise de similitude, classificação hierárquica descendente - CHD e análise fatorial de correspondência - AFC, as quais são apresentadas e discutidas na sequência.

\section{ANÁLISE LEXICOGRÁFICA E NUVEM DE PALAVRAS}

$\mathrm{Na}$ análise lexicográfica clássica, são identificadas as formas ativas, denominação que as palavras recebem no Iramuteq conforme a frequência em que aparecem no corpus textual analisado. O Quadro 2 apresenta as 30 palavras de maior frequência, onde $f$ representa frequência.

Quadro 2 - Formas ativas geradas pelo Iramuteq de acordo com o corpus textual

\begin{tabular}{|c|c|c|c|c|c|c|}
\hline No & Formas ativas & $(\mathbf{f})$ & No & Formas ativas & (f) \\
\hline 1 & professor & 42 & 16 & disciplina & 13 \\
\hline 2 & matematica & 39 & 17 & construcao & 13 \\
\hline 3 & analisar & 38 & 18 & publicar & 12 \\
\hline 4 & conhecimento & 31 & 19 & professor_de_matematica & 11 \\
\hline 5 & curso & 27 & 20 & conteudo & 11 \\
\hline 6 & ensino & 24 & 21 & forma & 10 \\
\hline 7 & pesquisa & 22 & 22 & aprendizagem & 10 \\
\hline 8 & conhecimento_pedagogico_do & 22 & 23 & aluno & 10 \\
\hline 9 & conteudo & 21 & 24 & utilizar & 9 \\
\hline 10 & processo & 19 & 25 & partir & 9 \\
\hline 11 & shulman & 14 & 26 & licenciatura & 9 \\
\hline 12 & dado & 14 & 27 & Investigar & 9 \\
\hline 13 & praticar & 13 & 28 & formacao_inicial & 9 \\
\hline 14 & objetivo & 13 & 29 & formacao & 9 \\
\hline 15 & ensinar & 13 & 30 & Escola & 9 \\
\hline
\end{tabular}

Fonte: Relatório do software Iramuteq (2018). 
Graficamente, a análise lexicográfica é representada pela nuvem de palavras (Figura 2), na qual a frequência da palavra é proporcional ao tamanho da fonte; desse modo, palavras que aparecem com tamanho maior são aquelas de maior relevância no corpus textual, sendo estas classificadas de acordo com o indicador de frequência.

Figura 2 - Nuvem de Palavras do Corpus Textual

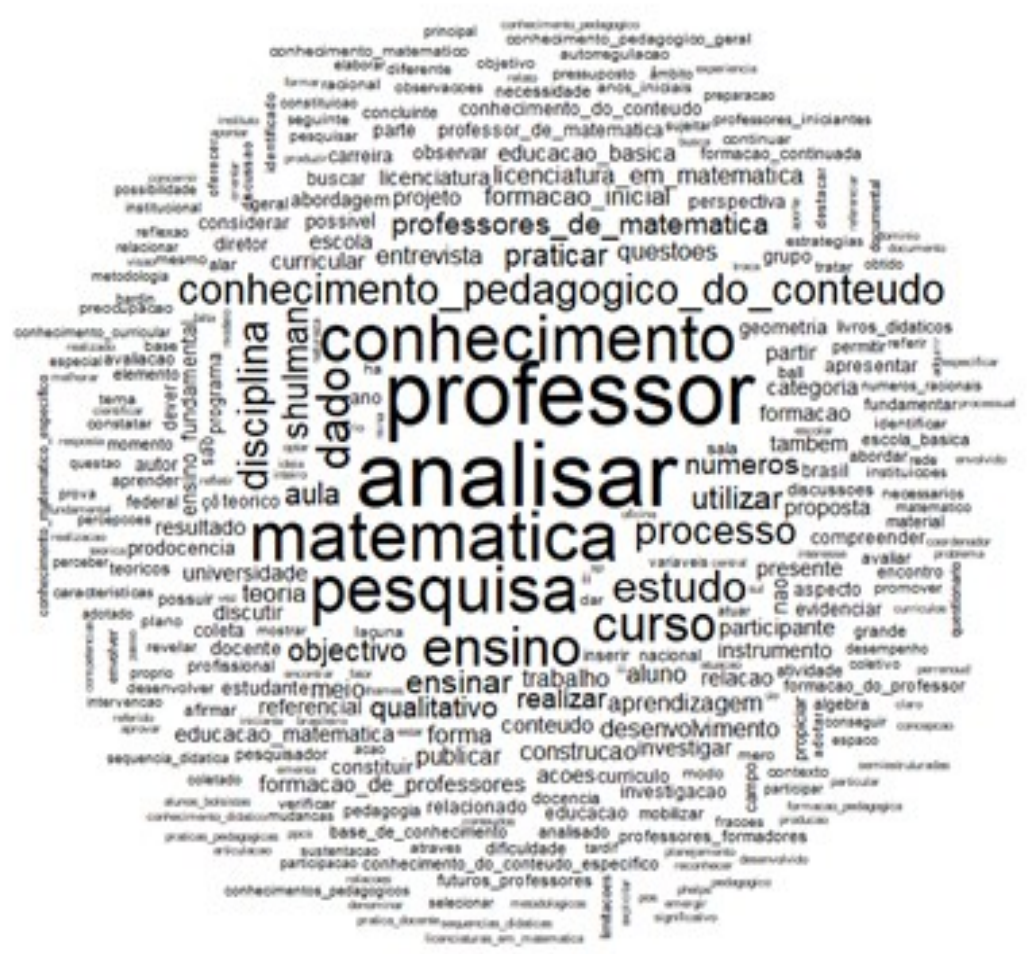

Fonte: Relatório do software Iramuteq (2018).

Visto que a revisão sistemática de literatura foi realizada com base nas produções acadêmicas publicadas no Brasil no formato de dissertações e de teses, relacionadas ao PCK no contexto da Licenciatura e da docência em Matemática, ficou evidente, na análise lexicográfica, a ênfase nas pesquisas das formas ativas: "professor" ( $f=42$ ), "matemática" ( $f=39$ ), "analisar" ( $f=38$ ), "conhecimento" ( $f=31$ ), "ensino" ( $f=24)$, "pesquisa" ( $f=22$ ), "conhecimento pedagógico do conteúdo" ( $f=22)$, "estudo" ( $f=21)$, "shulman" ( $f=14)$, "ensinar" ( $f$ $=13)$, "disciplina" ( $f=13)$, sendo estes os termos de maior frequência nas publicações mapeadas.

Na Figura 2, observa-se que as formas ativas, além de apresentarem maior frequência, localizaram-se de maneira destacada no centro da nuvem de palavras, revelando a forte relação entre elas e as demais que compõem o gráfico. A centralidade nas formas ativas "professor", "analisar", "conhecimento" e "matemática" permite inferir que a maioria das pesquisas mapeadas buscou analisar o professor de Matemática e os seus conhecimentos para o ensino nessa disciplina. Além disso, a nuvem de palavras demonstra que o referencial teórico de Shulman, referente ao Conhecimento Pedagógico do Conteúdo, fundamentou as pesquisas mapeadas. 


\section{ANÁLISE DE SIMILITUDE E ÁRVORE MÁXIMA}

A Análise de Similitude do software Iramuteq fundamenta-se na teoria dos grafos para identificar e representar a ligação ou a conexidade entre as formas ativas do corpus textual, de forma que a proximidade, a quantidade e a espessura das ligações, apontam a sua maior ou menor conexidade, possibilitando inferir sobre a estrutura de construção do texto e dos temas abordados nas pesquisas.

A Figura 3 corresponde ao grafo denominado no Iramuteq de Árvore Máxima ou de Similitude, e é resultante da Análise de Similitude do corpus textual considerado nesta revisão sistemática. Nela, é possível perceber o destaque para as formas ativas: "professor", "matemática", "análise", "processo", "pesquisa", "conhecimento pedagógico do conteúdo", "Shulman", "ensino", "conhecimento", "curso", e as que delas se aproximam, assim como a respectiva conexidade entre elas.

Figura 3 - Árvore Máxima de Similitude do Corpus Textual

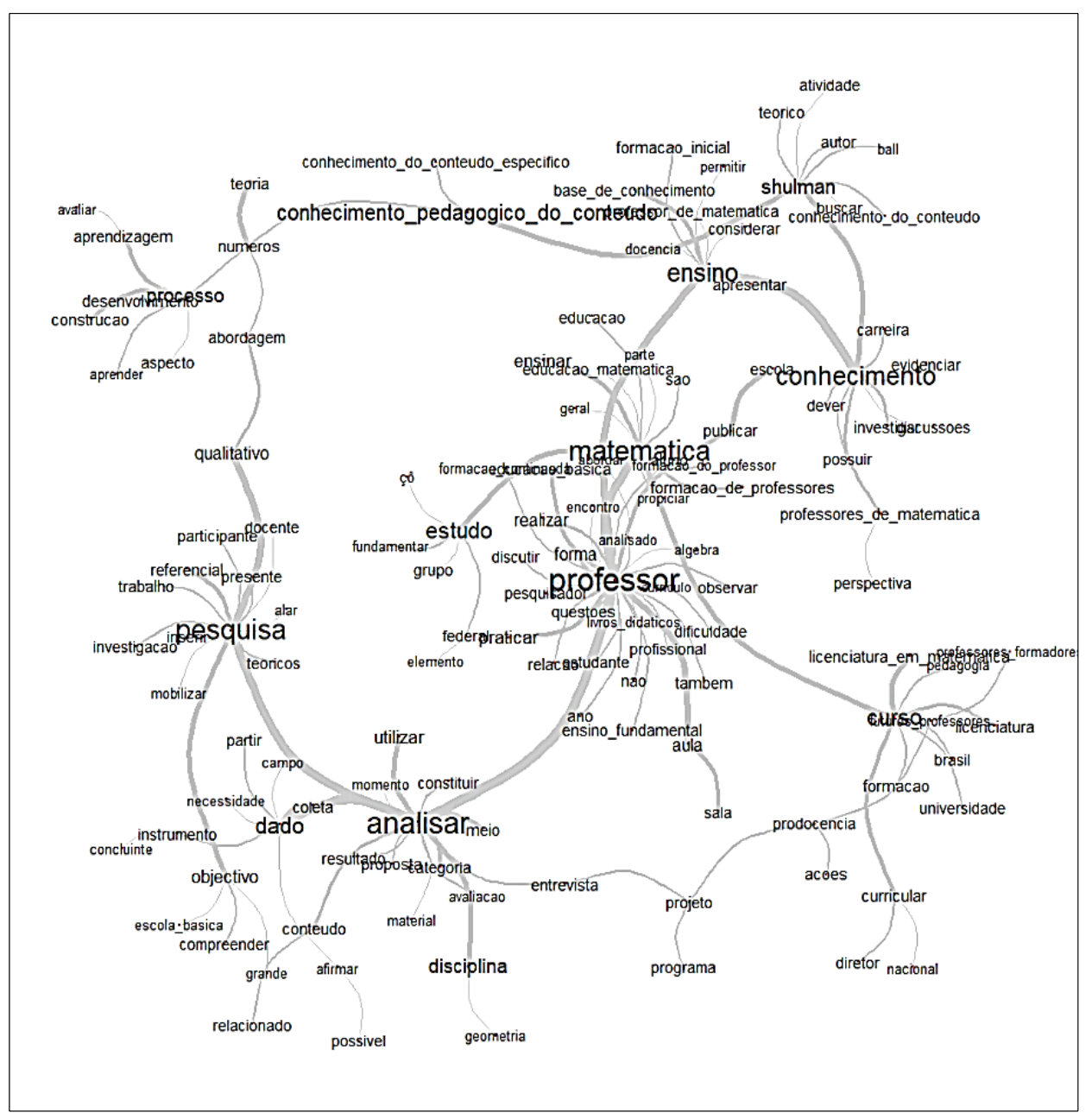

Fonte: Relatório do software Iramuteq (2018).

A árvore máxima apresentada na Figura 3 demonstra que as formas ativas "professor" e "matemática" ocuparam a posição central, e que as conexidades mais expressivas foram com as formas ativas "ensino", "conhecimento", "conhecimento pedagógico do conteúdo", "Shulman", "pesquisa" e "analisar", 
possibilitando a interpretação de que as pesquisas mapeadas tiveram o objeto de investigação centralizado na análise do Conhecimento Pedagógico do Conteúdo do Professor de Matemática.

Dois blocos menores de conexões destacam-se. No primeiro, situado na extremidade superior direita, a forma ativa "ensino" conecta-se de forma expressiva com "conhecimento", "Shulman" e "conhecimento pedagógico do conteúdo"; e, nas suas respectivas proximidades, situam-se os termos "formação inicial", "base de conhecimento", "conhecimento do conteúdo", "docência", "escola", "professor de matemática", dentre outros. Esse bloco, com exceção do centro, é o mais denso, com quantidade maior de formas ativas conectadas entre si. O segundo bloco localiza-se no extremo inferior direito e tem a forma ativa "curso" conectando-se à "matemática". No seu entorno, apresentam-se os termos "licenciatura em Matemática", "professores formadores", "formação", "universidade", dentre outros.

É possível perceber que o primeiro conjunto de conexões mencionado se interliga ao segundo de duas formas: perpassando por "matemática" e "professor"; ou, então, interligando-se a "processo", "pesquisa" e "analisar". Todavia, nota-se que o primeiro - aquele que concentra as formas ativas mais voltadas ao Conhecimento Pedagógico do Conteúdo e ao conhecimento específico de Matemática do professor - não se interliga diretamente àquele que concentra as formas ativas que se referem à universidade, à formação, aos cursos de Licenciatura em Matemática e ao professor formador.

Daí pode-se inferir sobre a existência de uma lacuna nas pesquisas nesse sentido, lacuna esta que aparece inclusive na análise empírica que originou os quatro agrupamentos das pesquisas (Tabela 2), visto que, em tal agrupamento, não foram identificadas pesquisas sobre o PCK no contexto dos cursos de Licenciatura em Matemática que tivessem considerado a perspectiva do professor formador.

Dessa maneira, as pesquisas que vêm sendo desenvolvidas na área da Matemática sobre o PCK têm o foco nos professores já formados e atuantes nas escolas e não nos professores do Ensino Superior. Isso demonstra a carência tanto de trabalhos que consideram a Base de Conhecimentos para Docência e o PCK do professor formador, como também daqueles que objetivam compreender a influência dos conhecimentos desses profissionais na formação inicial de professores de Matemática.

\section{ANÁLISE PELO MÉTODO DA CLASSIFICAÇÃO HIERÁRQUICA DESCENDENTE (CHD)}

A análise pelo método da Classificação Hierárquica Descendente (CHD) constitui-se como uma das mais importantes, rigorosas e assertivas possibilitadas pelo software Iramuteq. Essa análise consiste em um agrupamento que o software realiza das formas ativas, conforme a correlação existente entre elas, formando um esquema hierárquico de classes de vocabulários, a partir do teste estatístico de associação qui-quadrado ${ }^{4}$, cujos resultados são representados em uma figura denominada dendograma ${ }^{5}$ (Figura 4). Cada partição do dendograma representa uma classe de agrupamento de palavras que apresentam forte associação. 
Figura 4 - Dendograma de classes do corpus textual analisado

\begin{tabular}{|c|c|c|c|}
\hline Classe 1 & Classe 4 & Classe 3 & Classe 2 \\
\hline $20 \%$ & $24,6 \%$ & $26,9 \%$ & $28,5 \%$ \\
\hline $\begin{array}{l}\text { partir } \\
\text { conhecimento_peda } \\
\text { gogico_do_conteudo } \\
\text { dado } \\
\text { ball } \\
\text { categoria } \\
\text { shulman } \\
\text { conhecimento_do_conteudo } \\
\text { conhecimento_pedagpgico_g } \\
\text { eral } \\
\text { conhecimentos_pedagogicos } \\
\text { conhecimento_curricular } \\
\text { coletado } \\
\text { pedagogico } \\
\text { praticar } \\
\text { pesquisador } \\
\text { reflexao }\end{array}$ & $\begin{array}{l}\text { aprendizagem } \\
\text { processo } \\
\text { construcao } \\
\text { identificado } \\
\text { autorregulacao } \\
\text { permitir } \\
\text { avaliar } \\
\text { siquencia_didatica } \\
\text { carreira } \\
\text { base_de_conhecimentos } \\
\text { variaveis } \\
\text { sustentacao } \\
\text { obtido } \\
\text { formacao_inicial } \\
\text { perspectiva } \\
\text { considerar } \\
\text { resultado }\end{array}$ & $\begin{array}{l}\text { professor } \\
\text { publicar } \\
\text { aula } \\
\text { escola } \\
\text { educação_basica } \\
\text { ensino_fundamental } \\
\text { livro_didatico } \\
\text { grande } \\
\text { rede } \\
\text { numeros_racionais } \\
\text { atuar } \\
\text { forma } \\
\text { objetivo } \\
\text { sala } \\
\text { necessarios } \\
\text { preparacao }\end{array}$ & $\begin{array}{l}\text { Curso } \\
\text { licenciatura } \\
\text { prodocencia } \\
\text { futuros_professores } \\
\text { proposta } \\
\text { professores_formadores } \\
\text { brasil } \\
\text { disciplina } \\
\text { curricular } \\
\text { mudancas } \\
\text { relacao } \\
\text { preocupacao } \\
\text { referido } \\
\text { licenciatura_em_matematica } \\
\text { instituto } \\
\text { formacao_pedagogica }\end{array}$ \\
\hline
\end{tabular}

Fonte: Relatório do software Iramuteq (2018).

Note-se, na Figura 4, que a primeira partição feita pelo software Iramuteq deu origem à Classe 1, a qual representa (20\%) das formas ativas do corpus textual analisado. Essa classe subdividiu-se em dois subcorpus: a Classe 4, que contém $(24,6 \%)$ do corpus textual; e as Classes 3 e 2, com $(26,9 \%)$ e $(28,5 \%)$ respectivamente.

As quatro classes geradas contêm as formas ativas representadas também em letras de diferenciados tamanhos, dispostas em ordem decrescente, correspondendo aos valores do teste de associação qui-quadrado, gerado nos relatórios do Iramuteq, conforme sua maior aderência na classe e entre as classes. Assim sendo, cada uma das classes aponta aspectos das produções acadêmicas analisadas.

Observa-se, no dendograma, que as quatro classes têm ligação entre si, e em cada uma delas estão presentes aspectos das pesquisas mapeadas sobre o Conhecimento Pedagógico do Conteúdo, o que possibilita denominá-las de acordo com a apresentação das palavras pelos maiores valores do teste de associação qui-quadrado $\left(\chi^{2}\right)$, conforme segue.

a) Conhecimento Pedagógico do Conteúdo (Classe 1): as formas ativas de maiores valores de qui-quadrado e, portanto, com forte associação, remetem para o foco das pesquisas no conhecimento pedagógico do conteúdo $\left(\chi^{2}=31,52\right)$, dado $\left(\chi^{2}=25,94\right)$, e para o referencial que aborda as categorias da Base de Conhecimentos para a docência: Shulman $\left(\chi^{2}=19,23\right)$, conhecimento do conteúdo $\left(\chi^{2}=16,51\right)$, conhecimento pedagógico geral $\left(\chi^{2}=16,51\right)$, conhecimentos pedagógicos $\left(\chi^{2}=16,51\right)$, conhecimento curricular $\left(\chi^{2}=12,83\right)$; 
b) processo de aprendizagem da docência (Classe 4): essa classe, articulada fortemente com a Classe 1 , ao ressaltar as formas ativas, aprendizagem $\left(\chi^{2}=33,18\right)$, processo $\left(\chi^{2}=28,87\right)$, construção $\left(\chi^{2}=28,87\right)$, autorregularão $\left(\chi^{2}=15,92\right)$, base de conhecimento $\left(\chi^{2}=9,40\right)$, formação inicial , $\left(\chi^{2}=9,2\right)$, remete à aprendizagem da docência como objeto de estudo das produções acadêmicas mapeadas;

c) atuação do professor (Classe 3): as palavras dessa classe com maior valor de qui-quadrado apontam para a prática dos professores e para as questões voltadas ao ensino de Matemática. Ao ressaltar as formas ativas professor $\left(\chi^{2}=28,8\right)$, aula $\left(\chi^{2}=26,25\right)$, Educação Básica $\left(\chi^{2}=23,14\right)$, Ensino Fundamental $\left(\chi^{2}=12,99\right)$, livro didático $\left(\chi^{2}=11,20\right)$, atuar $\left(\chi^{2}=\right.$ $11,20)$, forma $\left(\chi^{2}=10,21\right)$, reparação $\left(\chi^{2}=8,33\right)$, confirmam que, nas pesquisas mapeadas, houve maior interesse em pesquisar o tema com foco no professor cuja atuação centra-se na Educação Básica;

d) formação de professores (Classe 2): essa classe apresenta forte articulação com a Classe 3. Todavia, volta-se à Licenciatura, para formação dos futuros professores e atuação dos professores formadores. Chama atenção, nessa classe, as formas ativas: curso $\left(\chi^{2}=29,39\right)$, licenciatura $\left(\chi^{2}=17,34\right)$, prodocência $\left(\chi^{2}=15,81\right)$, futuros professores $\left(\chi^{2}=15,81\right)$, professores formadores $\left(\chi^{2}=13,07\right)$, mudança $\left(\chi^{2}=10,37\right)$, preocupação $\left(\chi^{2}=7,72\right)$ e formação pedagógica $\left(\chi^{2}=7,71\right)$.

A análise pelo método da CHD demonstrou que a representatividade das Classes 3 e 2 na análise do corpus textual soma $(55,4 \%)$ das palavras ativas, valores que revelam forte correlação da formação com a atuação docente, o que demonstra a relevância de processos formativos de professores que considerem a indissociabilidade destes dois domínios: formação e atuação profissional.

Além disso, o dendograma apresentado na Figura 4 mostra que o foco das pesquisas mapeadas centrou-se no Conhecimento Pedagógico do Conteúdo, e que as formas ativas dessa classe correlacionam-se fortemente com a classe que se refere ao processo de aprendizagem da docência, no qual a Base de Conhecimentos seja considerada na perspectiva da formação inicial.

\section{ANÁLISE FATORIAL DE CORRESPONDÊNCIA (AFC)}

A última análise realizada pelo software Iramuteq considerada nesta revisão sistemática, refere-se à Análise Fatorial de Correspondência (AFC). Nessa análise, é realizado o cruzamento entre o vocabulário (considerando a frequência e a incidência de palavras) e as classes ${ }^{6}$. Por meio dessa análise, é possível visualizar os dados em um plano fatorial, em comparação com algumas variáveis que foram selecionadas na organização do corpus textual, e, também, notar a proximidade e a oposição entre as classes ou as palavras.

A Figura 5 mostra o plano fatorial gerado a partir das classes decorrentes da CHD. Os agrupamentos que correspondem à atuação de professores (Classe $3 \mathrm{da}$ $\mathrm{CHD}$ ) e os processos de aprendizagem da docência (Classe 4 da CHD), encontramse no eixo horizontal em quadrantes opostos, e apresentam $35,65 \%$ de variância. São apresentadas as classes 1, 2, 3 e 4 em vermelho, verde, azul e roxo, respectivamente. 
Figura 5 - Análise Fatorial de Correspondência do Corpus Textual

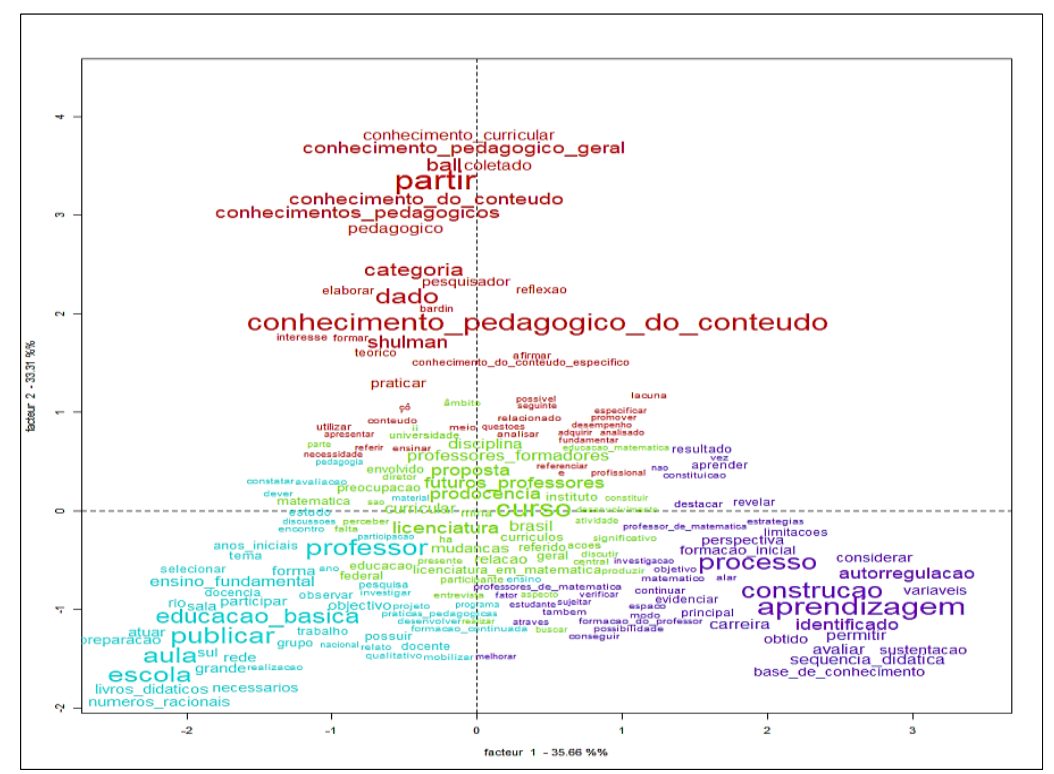

Fonte: Relatório do software Iramuteq (2018).

Oposto aos dois agrupamentos citados e compondo os dois quadrantes superiores do plano fatorial, encontra-se o Conhecimento Pedagógico do Conteúdo (Classe 1), representado pela cor vermelha, localizado no eixo vertical. Além de opostos, são agrupamentos que se localizam distantes, correspondendo a contextos semânticos específicos, que se referem à raiz semântica da palavra que mais inferiu na classe.

As formas ativas que se destacam na Classe 1 constituem aspectos que integram a Base de Conhecimentos para docência segundo o referencial de Lee Shulman (conhecimento pedagógico geral, conhecimento pedagógico do conteúdo, conhecimento curricular), indicando a fundamentação teórica adotada nas pesquisas que compõem esta revisão de literatura.

No centro do plano fatorial e presente nos quatro quadrantes, está a Classe 2 , representada na cor verde, correspondente à formação inicial de professores de Matemática, em cursos de Licenciatura no contexto brasileiro. A atuação dos professores formadores e a preocupação com o currículo do curso e com a formação dos futuros professores remetem à relevância do processo de aprendizagem da docência como objeto de estudo das produções acadêmicas mapeadas. Salienta-se que as Classes 3 e 4 apresentam as formas ativas mais concentradas e mais próximas da Classe 2.

A análise fatorial de correspondência permite inferir que as produções acadêmicas que integram esta revisão de literatura estão fundamentadas na Base de Conhecimentos para docência de Lee Shulman, com centralidade dos estudos no Conhecimento Pedagógico do Conteúdo (PCK). Revelam, também, que há certa prevalência de investigações sobre o PCK dos professores que atuam na Educação Básica, em relação à formação inicial dos licenciados e à ausência de pesquisas sobre o PCK de professores formadores. 


\section{CONSIDERAÇÕES FINAIS}

A análise das pesquisas brasileiras que integram esta revisão de literatura permite traçar o panorama de como os pressupostos da Base de Conhecimentos para Docência, em particular o Conhecimento Pedagógico do Conteúdo, vem se desenvolvendo nas pesquisas sobre formação e atuação de professores de Matemática.

Os resumos analisados nas categorias organizadas, conforme as similaridades dos objetos de investigação e no corpus textual pelo software Iramuteq, evidenciaram que o foco das pesquisas está voltado à formação inicial e continuada de professores, para a aprendizagem da docência, para a atuação do professor na Educação Básica e para análise de currículos e de Projetos Pedagógicos dos Cursos de Licenciatura em Matemática.

No entanto, ainda que a Base de Conhecimentos para docência e o PCK se constituam em um referencial teórico relevante no que diz respeito aos processos formativos de professores, no contexto do Ensino Superior, as pesquisas nesse aspecto ainda são desenvolvidas em menor quantidade, configurando-se basicamente em investigações que abordam a perspectiva dos licenciandos.

Em síntese, os achados desta revisão sistemática de literatura apontam que:

a) no recorte temporal de 2001 a 2018, houve o predomínio de publicações de dissertações $(61,9 \%)$ em relação a teses $(38,1 \%)$;

b) em relação ao objeto de estudo voltado ao Conhecimento Pedagógico do Conteúdo, foi maior a porcentagem das pesquisas com foco na Educação Básica (38,1\%); seguida daquelas que investigaram o PCK na formação inicial de professores de Matemática $(23,8 \%)$ e das que focaram nos currículos e nos Projetos Pedagógicos de Cursos de Licenciatura em Matemática (23,8\%); e, finalmente, daquelas que buscaram investigar a temática na formação continuada de professores de Matemática $(14,3 \%)$;

c) no contexto da Licenciatura e da docência em Matemática, as primeiras produções utilizando o referencial foram no ano de 2007, sendo uma tese e duas dissertações;

d) o período de maior produção foi nos anos de 2014 (23,8\%) e 2015 $(19,1 \%)$;

e) a análise lexicográfica demonstrou que as formas ativas com maior frequência foram: "professor", "matemática", "analisar" e "conhecimento", relacionadas principalmente aos estudos sobre o PCK nos processos de ensino;

f) no centro da árvore máxima, resultante da análise de similitude, ficaram em destaque as formas ativas "professor" e "matemática", demonstrando conexidade com as formas ativas "conhecimento", "ensino", "Shulman", "conhecimento pedagógico do conteúdo", "processo", "pesquisa", "analisar", e "curso";

g) a análise de classificação hierárquica descendente (CHD) mostrou quatro classes de formas ativas, dentre as quais se constata a forte correlação e 
aderência entre as Classes 3 e 2, evidenciando a relevância do tema em relação à atuação e à formação de professores de Matemática.

h) a análise fatorial de correspondência (AFC) permitiu visualizar o plano fatorial gerado a partir das classes decorrentes da CHD, evidenciando que as produções acadêmicas que integram a revisão sistemática se fundamentam na Base de Conhecimentos para a docência, com centralidade no PCK.

As análises mostraram que, embora as pesquisas no recorte temporal considerado, desenvolvidas a partir da utilização do referencial teórico que versa sobre o PCK, tenham sido expressivas na área da docência e da Licenciatura em Matemática em comparação a outras áreas de conhecimentos, este é um referencial que não aparece relacionado ao contexto da formação inicial de professores de Matemática segundo a perspectiva do professor formador. Desse modo, as pesquisas abordaram o tema considerando fundamentalmente a perspectiva dos professores que atuam em Matemática na Educação Básica (no Ensino Fundamental e Médio).

Pode-se inferir que a abordagem do PCK, em pesquisas com foco no professor formador atuante no Ensino Superior, tanto em disciplinas ou conteúdos específicos da Matemática, como também naquelas de natureza didático/pedagógicas, que objetivem compreender a influência dos conhecimentos desses profissionais na formação inicial de professores de Matemática, é ainda embrionária e constitui-se como a principal lacuna evidenciada nesta revisão sistemática sobre o tema.

Assim sendo, essa carência identificada nas produções acadêmicas aponta para um potencial campo de estudo e de novas pesquisas sobre a formação de professores de Matemática, no qual os conceitos da Base de Conhecimentos para Docência e do Conhecimento Pedagógico do Conteúdo representam um importante referencial para ser tomado por base teórica. 


\title{
Pedagogical content knowledge: scenario of brazilian research in the context of the mathematics teaching degree and mathematics teaching (2001-2018)
}

\begin{abstract}
This paper presents a systematic review of the literature regarding the Pedagogical Content Knowledge of professors in the context of the Mathematics teaching degree and Mathematics teaching. The research was carried out in the semester of 2018 with the objective of identifying the Brazilian academic production, theses and dissertations, based on the theoretical framework of Lee Shulman's Knowledge Base for Teaching, developed in the period from 2001 to 2018. The database used for the survey was the CAPES Portal of Dissertations and Thesis Catalog and library sites of the research institutions. Of the productions found, 21 were selected and their abstracts were analyzed in relation to the object of investigation. Thus, they were grouped according to the similarity of their themes. The abstracts of the academic productions were gathered and formed a textual corpus that was analyzed with the support of the Iramuteq software. The reports of lexicographic analysis, similitude analysis, descending hierarchical classification and factor analysis generated in the software demonstrated that, in the mapped research, the Pedagogical Content Knowledge was related to studies referring to the analysis of the curriculum of undergraduate teaching courses, initial and continuing education of professors, Mathematics teaching degree and Mathematics teaching and learning issues, predominantly from the perspective of Basic Education teachers. In summary, the systematic review made it possible to identify in which contexts, of the Mathematics teaching degree and Mathematics teaching, the Pedagogical Content Knowledge has been approached as a theoretical reference in the researches, revealing the investigation gap focused on the training of professors of the Mathematics teaching degree.
\end{abstract}

KEYWORDS: Pedagogical Content Knowledge. Mathematics teaching degree and Mathematics teaching. Training of professors. Systematic review. Iramuteq software. 


\section{NOTAS}

1 Neste artigo, optou-se pela utilização da sigla PCK ou Conhecimento Pedagógico do Conteúdo em vez do termo por extenso Pedagogical Content Knowledge. O termo, na língua inglesa, bem como a sua forma abreviada, foi proposto e utilizado por Lee Shulman desde o ano de 1983, referindo-se ao conhecimento necessário para o professor transformar um conhecimento específico sobre algum conteúdo em um conhecimento que seja compreensível pelos alunos; por isso, a denominação conhecimento pedagógico do conteúdo.

20 tutorial Iramuteq está disponível em: http://iramuteq.org/documentation/fichiers/tutoriel-portugais-22-11-2018.

3 Nos trechos, nos quadros ou nas figuras retirados do Iramuteq mantivemos a linguagem do Software - sem acentuação nas palavras.

4 Qui-Quadrado, simbolizado por $\left(\chi^{2}\right)$, é um teste de hipóteses que se destina a encontrar um valor da dispersão para duas variáveis nominais, avaliando a associação existente entre variáveis qualitativas. É um teste não paramétrico; assim, não depende dos parâmetros populacionais, como média e variância. Para aprofundamento, consultar Bussab e Morettin (2002).

5 "A partir dessas análises em matrizes o software organiza a análise dos dados em um dendograma da CHD, que ilustra as relações entre as classes. O programa executa cálculos e fornece resultados que nos permite a descrição de cada uma das classes, principalmente, pelo seu vocabulário característico (léxico) e pelas suas palavras com asterisco (variáveis). Além disto, o programa fornece uma outra forma de apresentação dos resultados, através de uma análise fatorial de correspondência feita a partir da CHD" (CAMARGO; JUSTO, 2013, p. 5).

6 De acordo com Nascimento e Menandro (2006), as Classes podem ser definidas como um agrupamento constituído por várias unidades de contexto elementar de vocabulário homogêneo.

\section{REFERÊNCIAS}

BATISTA, C. M. S. Percepções e conhecimentos de professoras que ensinam matemática nos anos iniciais do Ensino Fundamental acerca do ensino de números e operações. 2012. 148 f. Dissertação (Mestrado em Educação Matemática) - Universidade Federal do Mato Grosso do Sul, Campo Grande, 2012.

BUSSAB, W. O.; MORETTIN, P. A. Estatística Básica. 5. ed. São Paulo: Saraiva, 2002.

CAMARGO, B. V.; JUSTO, A. M. IRAMUTEQ: um software gratuito para análise de dados textuais. Temas em Psicologia, Ribeirão Preto, v. 21, n. 2, p. 513-

518, dez. 2013.

CORREIA, G. S. Estudo dos conhecimentos evidenciados por alunos dos cursos de licenciatura em Matemática e Física participantes do PIBID-PEC/SP. 2012. 
COSTA, D. E. O processo de construção de sequência didática como (pro)motor da educação matemática na formação de professores. 2013. 192 f. Dissertação (Mestrado em Educação em Ciências e Matemática) - Universidade Federal do Pará, Belém, 2013.

DAMICO, A. Uma investigação sobre a formação inicial de professores de Matemática para o ensino de números racionais no Ensino Fundamental. 2007. 313 f. Tese (Doutorado em Educação Matemática) - Pontifícia Universidade Católica de São Paulo, São Paulo, 2007.

DAVIES, P. Revisões sistemáticas e Campbell Collaboration. In: THOMAS, G.; PRING, R. (orgs.). Educação baseada em evidências: a utilização dos achados científicos para qualificação da prática pedagógica. Porto Alegre: Artmed, 2007. p. 31-43.

FANTINEL, P. C. A autorregulação da aprendizagem na formação de um Educador Matemático na modalidade a distância: uma proposta de articulação curricular. 2015. 233 f. Tese (Doutorado em Informática na Educação) Universidade Federal do Rio Grande do Sul, Porto Alegre, 2015.

FERREIRA, M. C. C. Conhecimento matemático específico para o ensino na Educação Básica: a álgebra na escola e na formação do professor. 2014. $184 \mathrm{f}$. Tese (Doutorado em Educação) - Universidade Federal de Minas Gerais, Belo Horizonte, 2014.

FURONI, S. P. Conhecimentos mobilizados por professores de Matemática do Ensino Médio em suas relações com livros didáticos. 2014. 156 f. Dissertação (Mestrado em Educação Matemática) - Universidade Federal do Mato Grosso do Sul, Campo Grande, 2014.

GARNIER, E. P. Análise de recursos didáticos na formação de professores de Matemática. 2015. 93 f. Dissertação (Mestrado Profissional em Matemática em Rede Nacional) - Universidade Federal do Rio de Janeiro, Rio de Janeiro, 2015.

GUERRA, M. F. O. A Licenciatura em Matemática nos Institutos Federais do Estado de Minas Gerais. 2013. 275 f. Tese (Doutorado em Educação Matemática) - Universidade Bandeirante Anhanguera, São Paulo, 2013.

LEITE, E. A. P. Formação inicial e base de conhecimento para o ensino de Matemática na perspectiva de professores iniciantes da Educação Básica. 2016. 269 f. Tese (Doutorado em Educação) - Universidade Federal de São Carlos, São Carlos, 2016.

LIMA, E. M. B. Um estudo sobre as disciplinas de Geometria em cursos de Licenciatura em Matemática. 2014. 136 f. Dissertação (Mestrado em Ensino de Ciências e Matemática) - Universidade Cruzeiro do Sul, São Paulo, 2014.

MACHADO, A. A. R. Saberes de professores de Matemática em início de carreira: egressos de uma instituição de Ensino Superior de Minas Gerais. 2017. 156 f. 
MAINARDES, J. A pesquisa sobre a organização da escolaridade em ciclos no Brasil (2000-2006): mapeamento e problematizações. Revista Brasileira de Educação, Rio de Janeiro, v. 14, n. 40, p. 7-23, abr. 2009.

MAROQUIO, V. S. Formação continuada de professores de Matemática: reflexões sobre o conhecimento pedagógico do conteúdo a partir da implantação das Diretrizes Curriculares. 2014. 172 f. Dissertação (Mestrado em Educação em Ciências e Matemática) - Instituto Federal do Espírito Santo, Vitória, 2014.

MATOS, D. V. A formação do professor que ensina Matemática nos anos iniciais: uma análise dos conhecimentos legitimados pelo MEC e sua operacionalização na prática. 2017. 162 f. Dissertação (Mestrado em Ciências e Matemática) Pontifícia Universidade Católica do Rio Grande do Sul, Porto Alegre, 2017.

NASCIMENTO, A. R. A.; MENANDRO, P. R. M. Análise lexical e análise de conteúdo: uma proposta de utilização conjugada. Estudos e Pesquisas em Psicologia, Rio de Janeiro, v. 6, n. 2, p. 72-88, jul./dez. 2006.

OLIVEIRA, E. A formação e a autoformação de professores de Matemática: implicações na prática pedagógica. 2016. 134 f. Dissertação (Mestrado em Educação em Ciências e Matemática) - Pontifícia Universidade Católica do Rio Grande do Sul, Porto Alegre, 2016.

RESENDE, M. R. Re-significando a disciplina teoria dos números na formação do professor de Matemática na Licenciatura. 2007. $281 \mathrm{f}$. Tese (Doutorado em Educação Matemática) - Pontifícia Universidade Católica de São Paulo, São Paulo, 2007.

SANTOS, E. A. dos; FREIRE L. I. F. Planejamento e aprendizagem docente durante o estágio curricular supervisionado. ACTIO, Curitiba, v. 2, n. 1, p. 263-281, jan./jul. 2017.

SHULMAN, L. S. Those who understand knowledge growth in teaching. Educational Researcher, Thousand Oaks, California, v. 15, n. 4, p. 4-14, 1986.

SHULMAN, L. S. Knowledge and teaching: foundations of a new reform. Harvard Educational Review, Harvard, v. 57, n. 1, p. 1-22, 1987.

SILVA, J. F. Um estudo do Programa de consolidação das Licenciaturas no contexto da Formação Inicial de professores de Matemática. 2017. 253 f. Tese (Doutorado em Educação Matemática) - Universidade Anhanguera de São Paulo, São Paulo, 2017.

SILVA, L. D. Conhecimentos presentes na disciplina de análise nos cursos de Licenciatura em Matemática no Brasil. 2015. 236 f. Tese (Doutorado em Educação Matemática) - Universidade Estadual Paulista Júlio de Mesquita Filho, Rio Claro, 2015.

SILVA, R. G. Interações entre licenciandos em Matemática e Pedagogia: Um olhar sobre o ensino do tema Grandezas e Medidas. 2010. 184 f. Dissertação 
(Mestrado em Educação Matemática) - Universidade Federal do Mato Grosso do Sul, Campo Grande, 2010.

SOUZA, D. S. A formação do professor de Matemática: um estudo sobre o conhecimento pedagógico dos números racionais. 2015. 149 f. Dissertação (Mestrado em Ensino, História e Filosofia das Ciências e Matemática) Universidade Federal do ABC, Santo André, 2015.

WOLSKI, D. T. R. M. O movimento das reformas curriculares da Licenciatura em Matemática na Universidade Federal do Paraná: algumas referências ao conhecimento pedagógico do conteúdo. 2007. 310 f. Dissertação (Mestrado em Educação) - Universidade Estadual do Paraná, Curitiba, 2007.

Recebido: 16 nov. 2019

Aprovado: 20 mai. 2020

DOI: 10.3895/actio.v5n2.11287

Como citar:

TEIXEIRA, O.; BRANDALISE, M. A. T. Conhecimento pedagógico do conteúdo: cenário das pesquisas brasileiras nos contextos da licenciatura e da docência em matemática (2001-2018). ACTIO, Curitiba, v. 5, n.

2, p. 1-21, mai./ago. 2020. Disponível em: <https://periodicos.utfpr.edu.br/actio>. Acesso em: XXX

Correspondência:

Odiméia Teixeira

Avenida Tiago Ribeiro Prado, nº 181, Village Solaris, Irati, Paraná, Brasil.

Direito autoral: Este artigo está licenciado sob os termos da Licença Creative Commons-Atribuição 4.0

Internacional.

(c) (i) 